\title{
Bidirectional Underwater Visible Light Communication
}

\author{
Arsyad Ramadhan Darlis, Andre Widura, Muhamad Rifan Andrian \\ Department of Electrical Engineering, Institut Teknologi Nasional Bandung, Indonesia
}

\begin{tabular}{l} 
Article Info \\
\hline Article history: \\
Received Feb 13, 2018 \\
Revised Jul 27, 2018 \\
Accepted Aug 15, 2018 \\
\hline Keyword: \\
Bidirectional \\
Color filter \\
RGB LEDs \\
Underwater \\
Visible Light Communication
\end{tabular}

\section{Corresponding Author:}

Arsyad Ramadhan Darlis,

Department of Electrical Engineering,

Institut Teknologi Nasional Bandung,

PKH. Mustapha Street No. 24 Bandung 40124, West Java, Indonesia.

Email: 1sntl@ccu.edu.tw

\begin{abstract}
In this paper, a novel bidirectional underwater visible light communication (BiUVLC) is proposed. The VLC transmitter transmits an information signal using the one of RGB LED through the water tank that represents an underwater environment and then is received by VLC receiver via a color filter. The color LEDs and color filters are utilized in bidirectional systems. The single link is created by a LED on the transmitter and the color filter on the receiver with the same color which represents a single wavelength. The performance of the proposed BiUVLC system was evaluated via implementations. The experimental result shows that the transmitted signal undergoes attenuation over the underwater optical channel and the pair of the blue wavelength in link 1 and the green wavelength in link 2 have the best performance than the other wavelength pair. In the crosstalk measurement, the red wavelength color is the worst in the underwater environment.
\end{abstract}

Copyright $@ 2018$ Institute of Advanced Engineering and Science. All rights reserved.

\section{INTRODUCTION}

Recently, there are marine devices and vehicles that are utilized in the underwater environment for many applications, such as oceanographic, pipeline survey in an offshore industry, and military, especially wireless sensor networks in an underwater environment [1]. Therefore, the two way or bidirectional communication system between devices and vehicles is a prerequisite. To address this need, several communication technologies have been presented using various transmission medium, i.e. acoustic communications, underwater radio frequency (RF) communications, and underwater visible light communications (UVLC). Acoustic communications are widely used in underwater communication because it has relatively low attenuation so the long distance communication, maximum up to $1 \mathrm{~km}$, can be achieved [2], [3]. The disadvantage of this technology is the high frequency communication cannot be done. While UVLC offers the highest data rate, up to $1 \mathrm{Gbps}$, and moderate coverage distance of up to $100 \mathrm{~m}$, considering RF supporting a distance of up to $10 \mathrm{~m}$ [2], [4]. Recently, the research in VLC has been addressed for many applications [5]-[14].

Research on communication technology in the underwater environment using visible light, by Dominic O'Brien [15] from the University of Oxford with his team in 2008, stated that the use of white LED lights has an advantage in terms of performance improvement as well the opportunity to provide information simultaneously. Followed by Jianyang Shi [3] from Fudan University with his team in 2014, performing realtime bidirectional communication using white LED phosphor bases with speeds of $100 \mathrm{Mbps}$ and $200 \mathrm{Mbps}$ using RGB LED. Bernando Miguel C. S. [16] applied visible light communication for underwater communication. In the study, he used a very bright blue LED, cyan and green on the transmitter and use a modified blue or green photodiode on the receiver. The results of his research obtained $1 \mathrm{Mbps}$ at a distance of 5 meters with delivery capabilities at sea and in the river. Another research conducted by Chao Wang [17] of the National Digital Switching System Engineering and Technological Research Center, Zhengzhou with 
his team, they applied visible light communication to underwater communication. By narrowing the halfpower corner of the Light Emitting Diode (LED) aimed at increasing the light intensity of the transmitter. The use of Single Photon Avalanche Diode (SPAD) on the receiver improves the detection sensitivity in this study. Therefore, to our knowledge, there has been no the bidirectional VLC (BiVLC) research in the underwater environment.

In this paper, a novel bidirectional underwater visible light communication (BiUVLC) is proposed. The systems are implemented by the two transceivers in an experimental method. And the proposed system utilizes the one of Red Green Blue (RGB) LED and a color filter that represents a wavelength to build the bidirectional systems. The bidirectional condition in optical communication occurs while each link using a wavelength which is represented by a color LED and a color filter. The proposed system utilized the water tank that represents the underwater environment. The first link, the VLC transmitter with the single color LED transmits an information signal through the water tank that represents an underwater environment and then is received by VLC receiver via a color filter. The same condition occurs for the second link where the information signal is transmitted from VLC transmitter toward VLC receiver using same or different color LED. The crosstalk measurement is used. Therefore, this research is prospective to give the contribution to finding the best of the color pair for the bidirectional VLC system in underwater environment. The proposed systems can support the bidirectional communication between vehicles, divers, and devices in the underwater environment.

\section{RESEARCH METHOD}

In this chapter, we will discuss about the steps in conducting the research of bidirectional visible light communication in underwater environment.

\subsection{System Design}

In designing this system, the two transceiver are used which comprises of 2 (two) transmitters and 2 (two) receivers. The equipment is combined to get a single link transceiver. Then put the LED light on the transmitter and photodiode on the receiver.

Figure 1 shows the block diagram of a visible light communication system, which consists of a transmit and receiving system. In the transmitter, the input section is given information in the form of an analog signal with the human frequency limit which is $400-4000 \mathrm{~Hz}$, generated by the audio generator. The signal processed on the transmitter circuit; then the information signal is transmitted through the light using the LED.

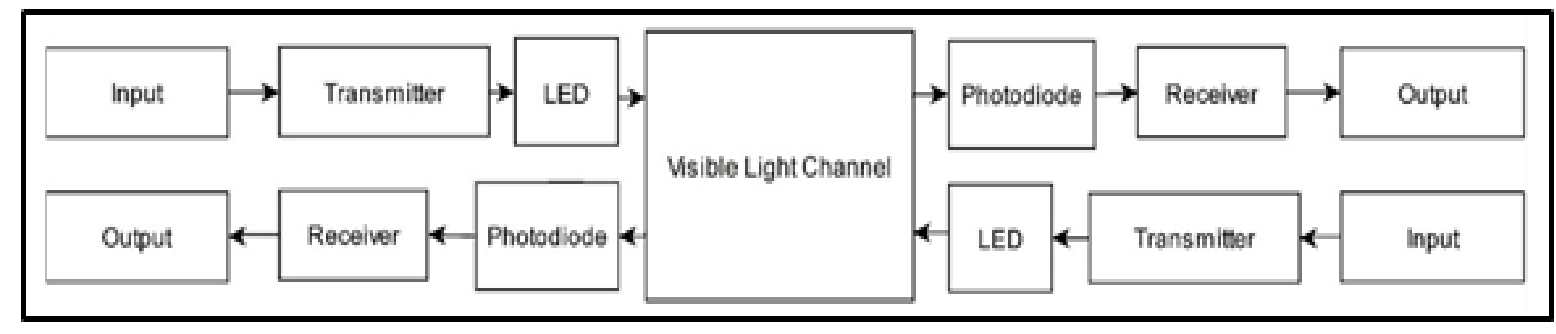

Figure 1. Block diagram system

The signal from transmitter undergoes a process of altering from an analog signal into the light through the Light Emitting Diode (LED). The light generated by the LED contains information from the transmitter. To proceed to the next section, the light contains information must be captured using components that can convert light into electricity. The part that can turn light into electrical are photosensors, and the one used in this design is a photodiode. The captured light by the photodiode contains information. Since the information received directly by the photodiode is too weak, the amplifier is used as a booster from the photodiode to forwarded to the receiver output.

\subsection{VLC Transmitter}

In the transmitter section, the process of information signal changes coming from the signal generator into the form of light, which will be transmitted through the color LED. At the time of sending information in the form of visible light waves, the LED will emit visible light according to the transmitter 
signal. The color of filters is to set the links to avoid wavelength interference. Figure 2 is a block diagram of the entire transmitter.

Figure 2 shows the connection between components in the transmitter system, input from the audio generator connected to the power amplifier then to the transformer and to the LED to transmit the signal. The voltage input used is 12 volts, the cathode on the LED is connected to the secondary transformer winding, for the primary transformer winding is connected to the power amplifier. The connection of these components can be seen in Figure 3 which is part of the transmitter with the specification:
a. Source
: Power Supply (12 V)
b. LED
c. Amplifier
: 5 mm (Everlight 334-15/T1C1-4WYA )
d. Transfomator
: Kit Power Amplifier
: Center Tap, Step Down, 0/CT 6-8-10-12 V

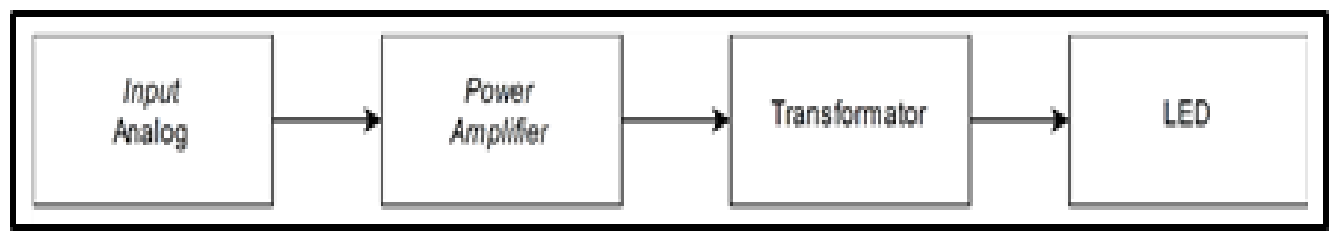

Figure 2. VLC transmitter diagram block

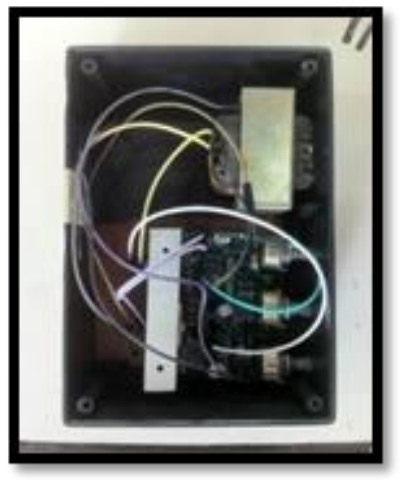

(a)

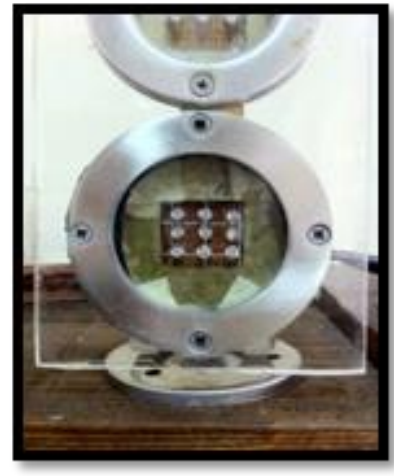

(b)

Figure 3. Transmitter (a) circuit (b) LEDs

\subsection{Receiver VLC}

In this receiver, the visible light that captured by the photodiode converted into an information signal. The workflow of this receiver section can see in Figure 4, the information transmitted captured by the photodiode proceeds to a circuit containing some resistor, capacitors, and bc547 transistors components, the component is a series of amplifiers. In the block diagram the captured light will be forwarded to the amplifier circuit to be amplified to a certain level, then the reinforced value will be displayed through the oscilloscope through the output of the amplifier. The circuit of receivers has specification:
a. Source : Power Supply (9 V)
b. Photodiode : $5 \mathrm{~mm}(\mathrm{SFH} 203)$
c. Transistor : BC547
d. Resistor : $100 \Omega, 1 \mathrm{k} \Omega, 1 \mathrm{M} \Omega, 470 \mathrm{k} \Omega, 56 \mathrm{k} \Omega, 3,3 \mathrm{k} \Omega$
e. Capasitor : $100 \mathrm{nF} 2 \mathrm{pcs}$ 


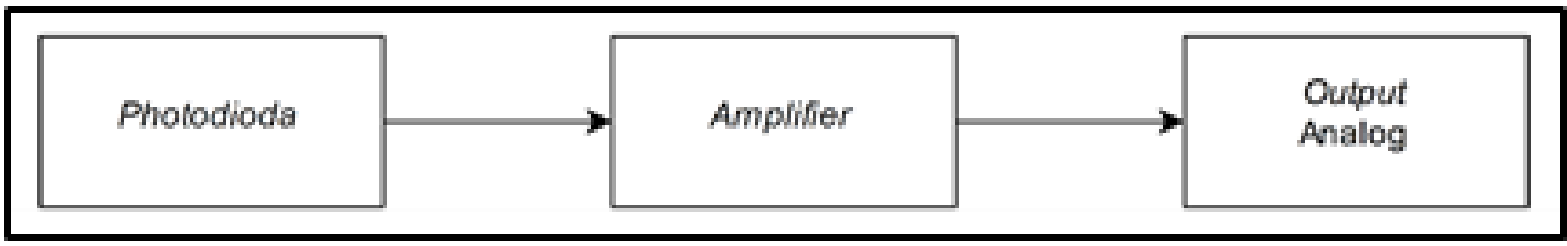

Figure 4. VLC receiver diagram block

Figure 5(a) shows the implementation for receiver circuit where output of the circuit will be sent to the oscilloscope and figure 5(b) is photodiode array.

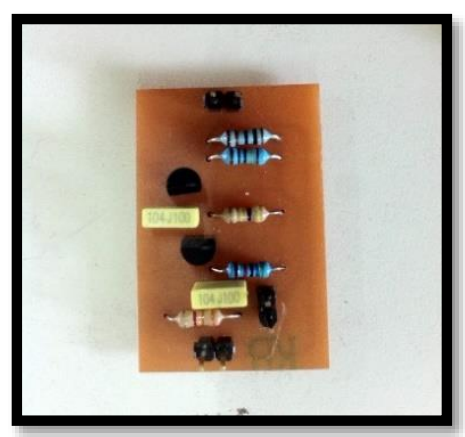

(a)

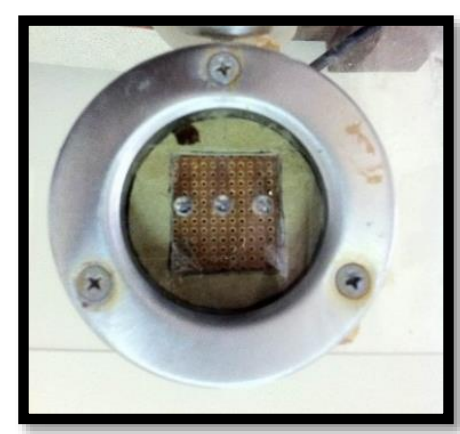

(b)

Figure 5. Receiver implementation (a) circuit (b) photodiode array

This channel model implements the workings of VLC in underwater. The aquarium with dimensions 190x40x40 cm coated by scotlights on the inner side of the aquarium, it aims to avoid the incoming outer light from the side of the tank, then covered with black corriboard so that no light enters at the top. Next aquarium filled with tap water with $35 \mathrm{~cm}$ high. Figure 6 is the concept and realisation of channel model implementation.

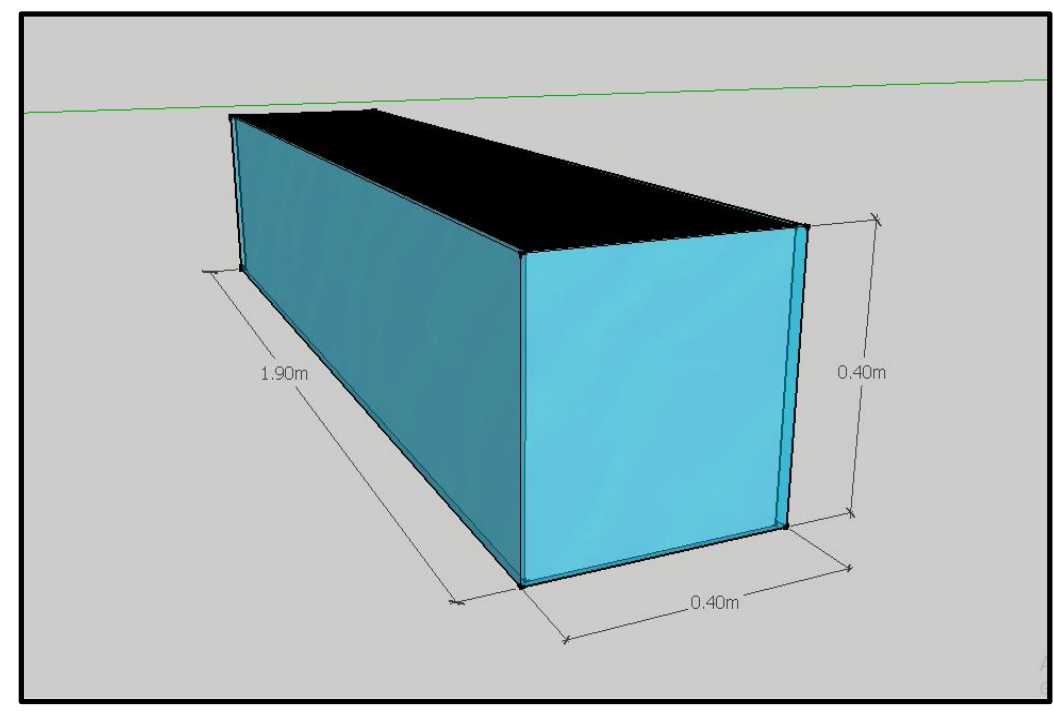

(a) 


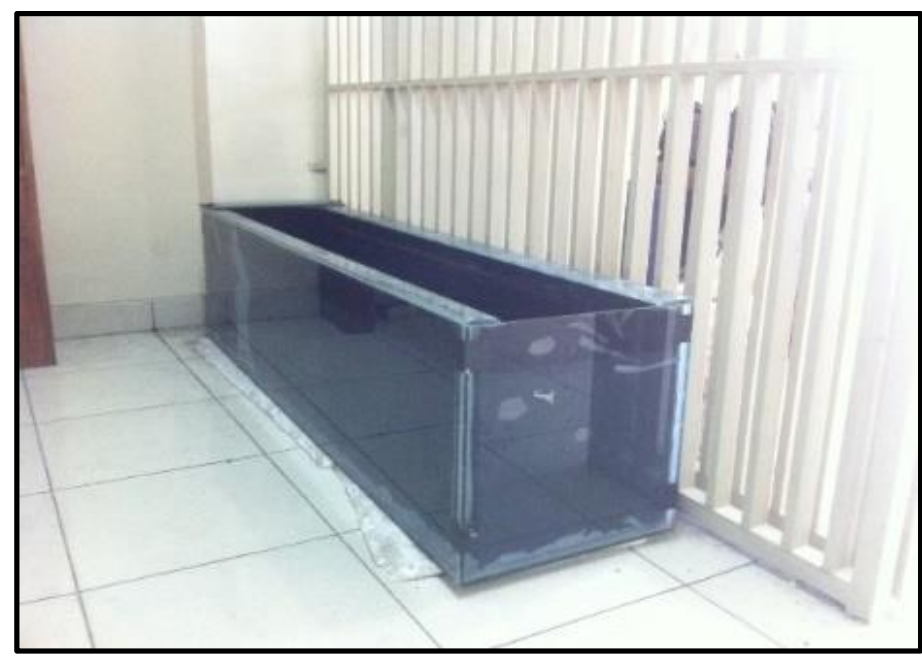

(b)

Figure 6. Prototype of channel model (a) design (b) implementation

\section{RESULTS AND DISCUSSION}

After the design process, the next step is to measurements. Measurements were made to obtain system performance data, then compared to determine the performance of a device that has been designed. The measurement results can be used as a reference in the overall analysis.

\subsection{Position based Measurement System}

On the measurement, the system is tested in two conditions. First transmitter 1 and transmitter two also receiver 1 and receiver 2 are on the same level or can be called crossed. The second situation, the position of transmitter 1 and receiver 1 and transmitter 2 and receiver 2 are on the same level or can be called directional. The purpose of this measurement is to know the optimal position in transmitting the information between links. Figures 7 and 8 are diagrammatic of both previously conditions.

Figure 9 show graph of measured values from the two previously mentioned conditions with frequency is $400-4000 \mathrm{~Hz}$ and $5 \mathrm{Vp}$ - p signal amplitude.

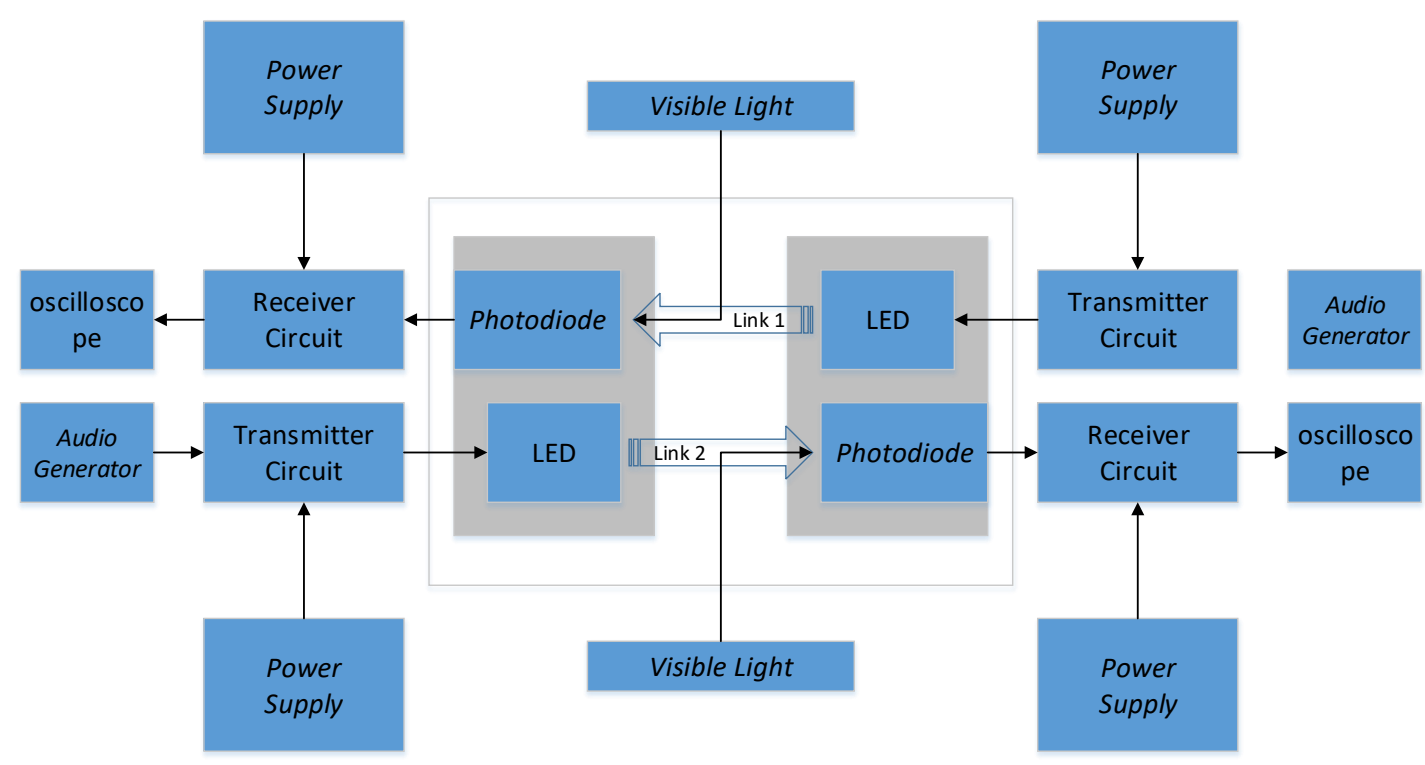

Figure 7. Block diagram system from directional measurement 


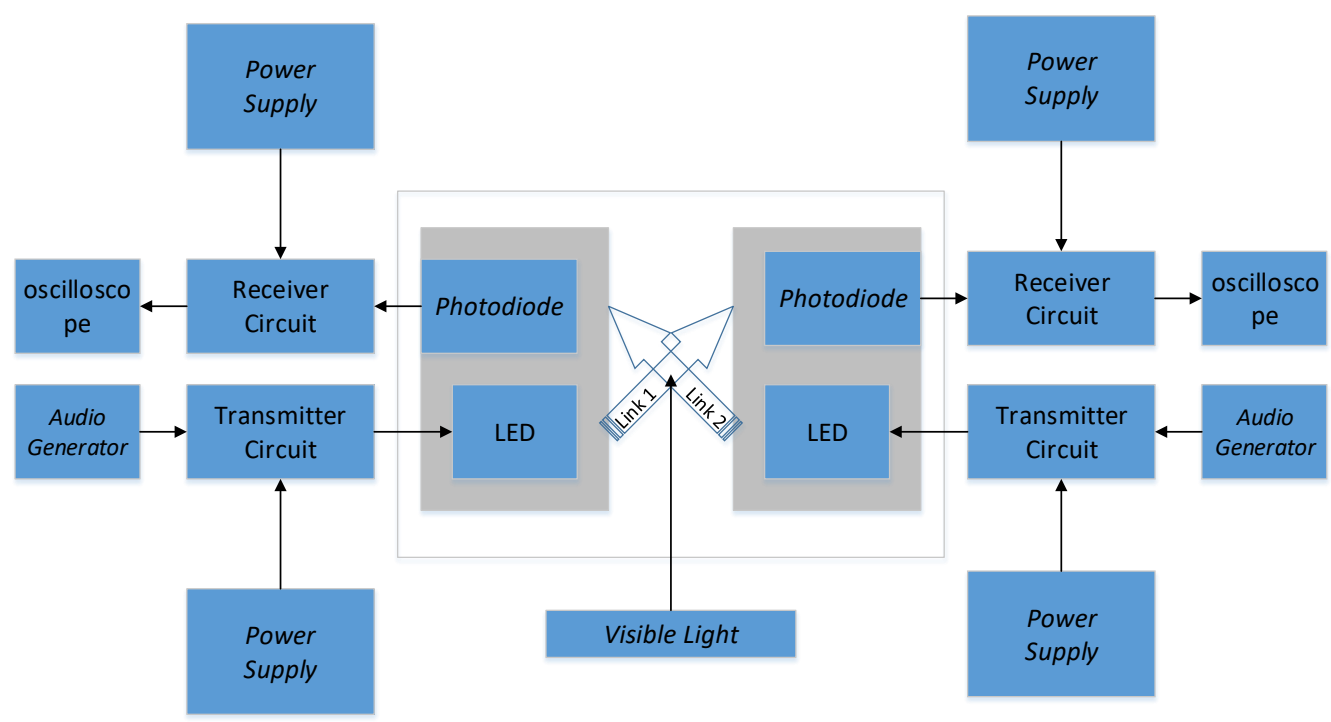

Figure 8. Block diagram system from cross measurement
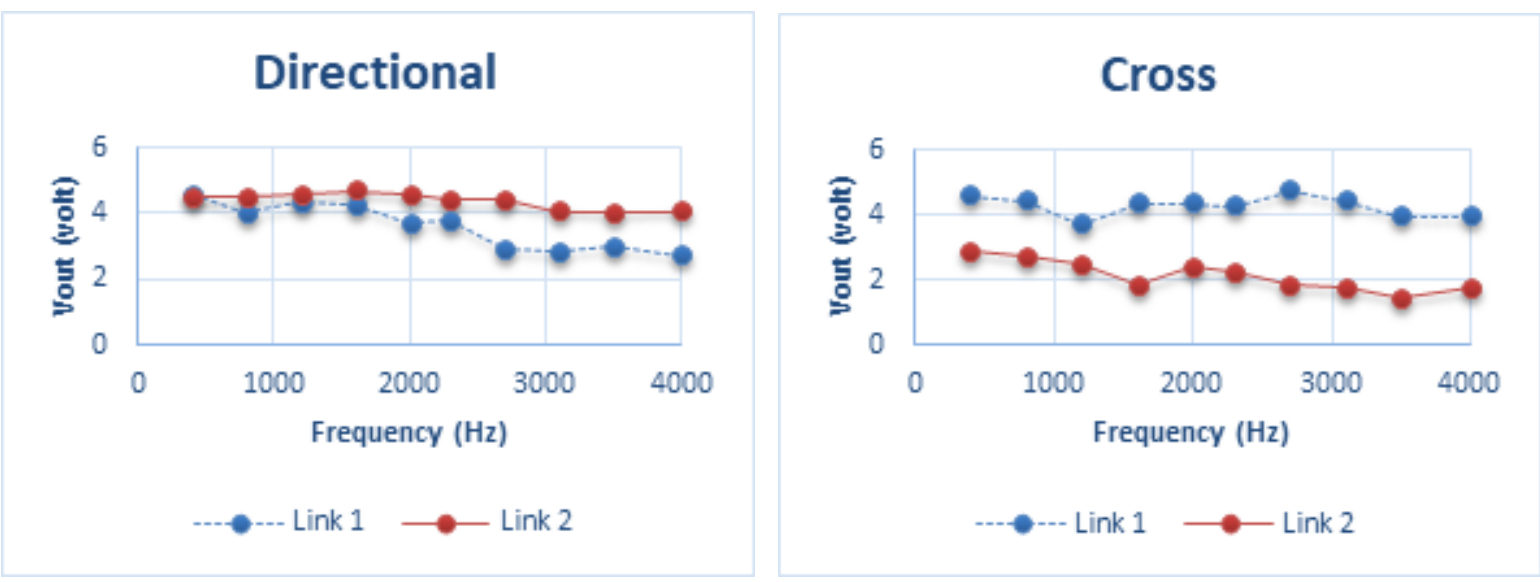

Figure 9. Position based measurement result

From the measurements on transmitter 1 and receiver 1 and transmitter 2 and receiver two positions in the same area display values that are not much different. In transmitter condition 1 and transmitter 2 and receiver 1 and receiver two are in the same area or can be called crossed shown that the values between links are much different. It can be assumed that directional position is the best condition on this system.

\subsection{Bidirectional Measurement using RGB LEDs}

The next measurement by using color LED on the transmitter side to compare. The color LED used as many as three pieces placed on the transmitter side and the receiver set a color LED similar to the color on the transmitter. Figure 10 is a block diagram in measurement using color LED. Measurements were made in water with a water depth of $35 \mathrm{~cm}$ with a distance between the links as far as $50 \mathrm{~cm}$. Each color is tested based on a frequency range of $400-4000 \mathrm{~Hz}$ with an amplitude of $5 \mathrm{Vp}$-p. Figure 11 shows the results of measurements using RGB LEDs. 


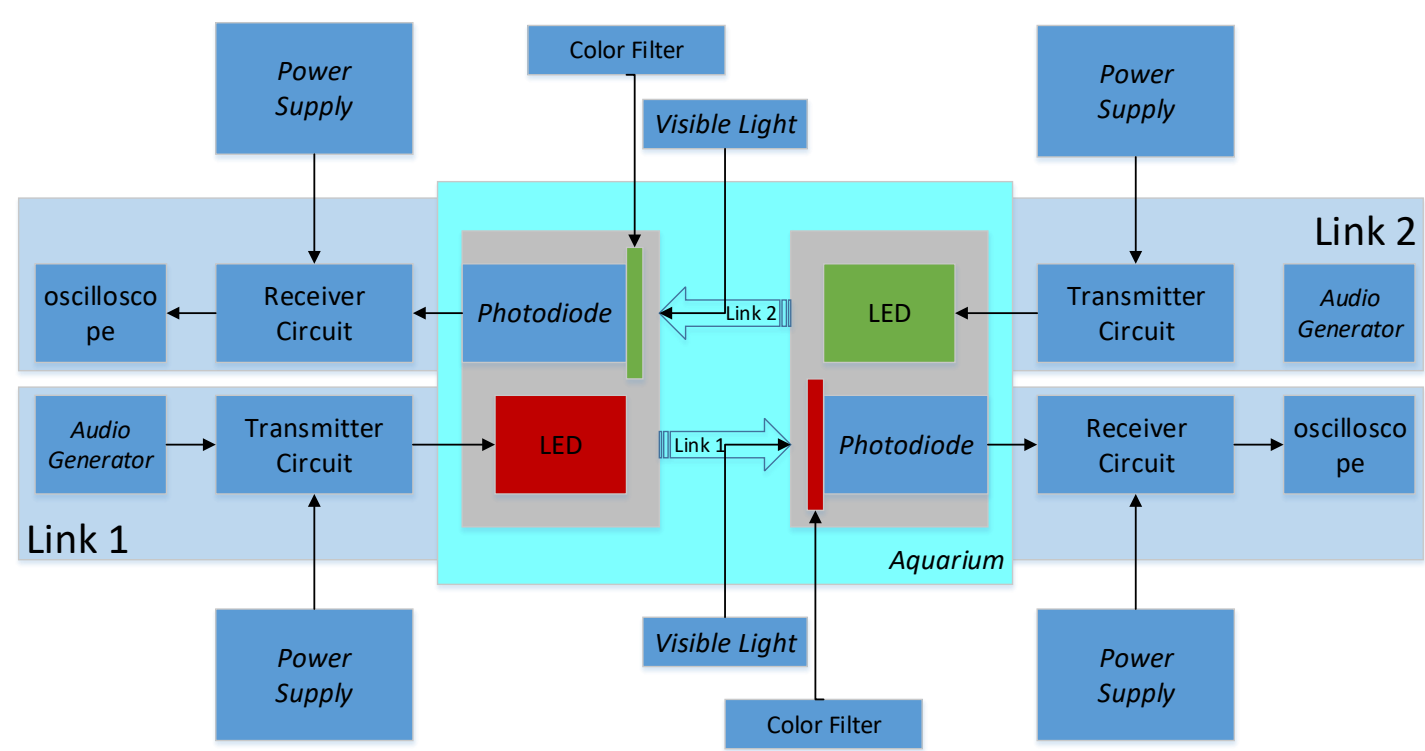

Figure 10. Diagram block of bidirectional measurement using RGB LEDs

In Figure 11, three graphs are showing the response of each link. The red line displays the response on link 2 and for the blue line represents the response on the link 1 . The explanation for writing the title of each graph "Red - Red" the first color mentioned is a link one which contained a color LED on the transmitter and color filters on the receiver it aims to obtain one wavelength in one link. On the second color after the "-" sign is a link 2 containing the color LED on the transmitter and the color filter on the receiver it aims to obtain one wavelength in one link. In this measurement, the use of filters and color LEDs on link two are changed interchangeably. Table 1 shows the average results of each measured link.

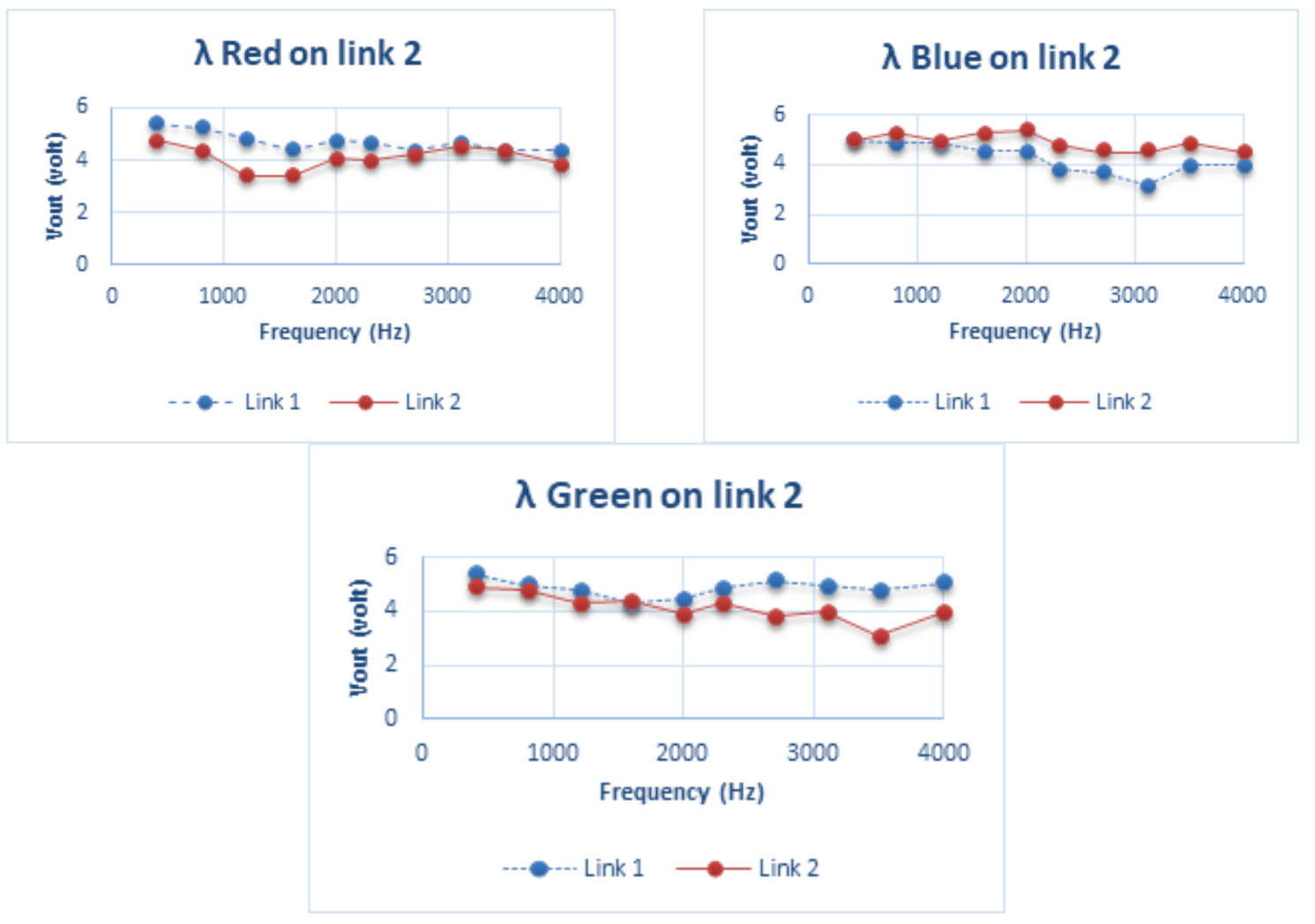

Figure 11. Measurement result where $\lambda$ red on link 1 
Table 1 is the average value of the output voltage on the receiver side of link 1 and link 2, to determine whether a solid color combination is seen from a large number of values between links. In Table 4 the "Red - Blue" color combination has the highest output voltage value of 8.50 volts.

Table 1 . Average of Measurement Value where $\lambda$ Red on Link 1

\begin{tabular}{cccc}
\hline$\lambda$ on link 2 & Red (volt) & Green (volt) & Blue (volt) \\
\hline Link 1 & 4.32 & 4.45 & 4.49 \\
Link 2 & 3.74 & 3.79 & 4.01 \\
Total & 8.06 & 8.24 & 8.50 \\
\hline
\end{tabular}

In Figure 12, three graphs are showing the response of each link. The red line displays the response on link 2 and for the blue line represents the response on the link 1. The explanation for writing the title of each graph "Blue-Blue" on the first color mentioned is a link one that contains color LEDs on the transmitter and color filters on the receiver it aims to get one wavelength in one link. In the second color after the "-" sign is a link 2 containing color LEDs on the transmitter and color filters on the receiver it aims to get one wavelength in one link.

Table 2 represents the average value of the output voltage on the receiver side of link 1 and link 2 , to determine whether a solid color combination is seen from a large number of values between links. In Table 5 the "Blue-Green" color combination has the highest output voltage value of 8.90 volts. Figure 12 addresses the results of measurements using color LEDs.

Table 2. Average of Measurement Value where $\lambda$ Blue on Link 1

\begin{tabular}{cccc}
\hline$\lambda$ on link 2 & Blue (volt) & Red (volt) & Green (volt) \\
\hline Link 1 & 4.44 & 3.73 & 4.05 \\
Link 2 & 3.80 & 4.47 & 4.85 \\
Total & 8.24 & 8.20 & 8.90 \\
\hline
\end{tabular}

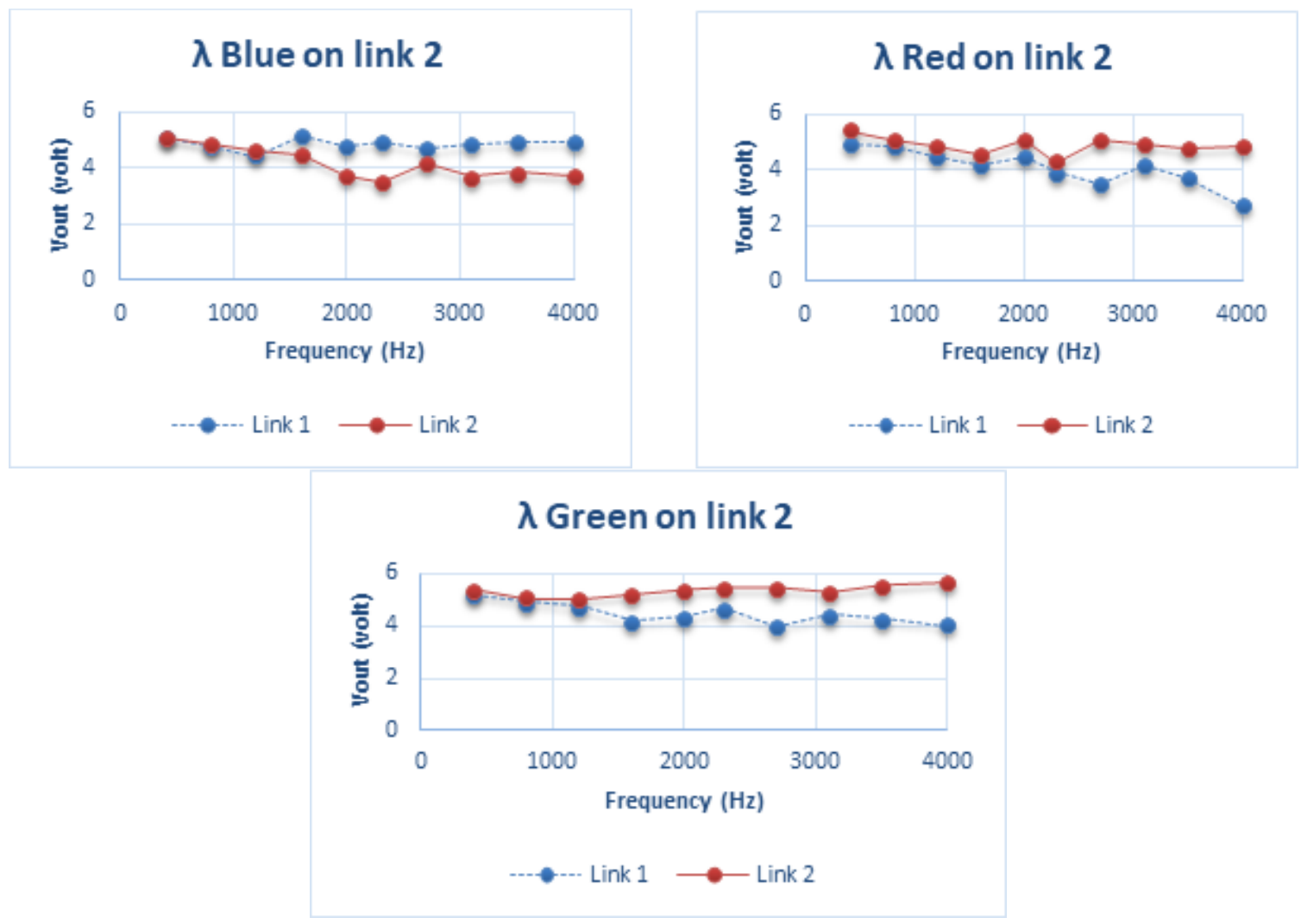

Figure 12. Measurement result where $\lambda$ blue on link 1 
In Figure 13, three graphs are showing the response of each link. The red line represents the response on link 2 and for the blue line represents the response on the link 1 . The explanation for writing the title of each "Green - Green" graph on the first color mentioned is a link one that contains color LEDs on the transmitter and color filters on the receiver it aims to get one wavelength in one link. In the second color after the "-" sign is a link 2 containing color LEDs on the transmitter and color filters on the receiver, it aims to get one wavelength in one link.

Table 3 is the average value of the output voltage on the receiver side of link 1 and link 2, to determine whether a solid color combination is seen from a large number of values between links. In Table 6 the "Green - Blue" color combination has the highest output voltage value of 8.78 volts. Based on the nine pairs of tested colors and from the data obtained, proving that a good color pair is used as link1 and link two on bidirectional communication is a "Blue-Green" color LED pair with a value of 8.90 volts. This result is obtained from a significant amount of output voltage at the receiver, and this conclusion can be corroborated by the literature that states the best wavelength in the underwater environment is the blue-green wavelength of $400-500 \mathrm{~nm}$ [2]. Based on the comparison in the use of filters and LEDs found that the color pair that produces a good response is on the color filter with a combination of blue and red with a value of 10 volt.

Table 3. Average of Measurement Value where $\lambda$ Green on Link 1

\begin{tabular}{cccc}
\hline $\boldsymbol{\lambda}$ on link 2 & Green (volt) & Red (volt) & Blue (volt) \\
\hline Link 1 & 4.42 & 3.88 & 4.05 \\
Link 2 & 3.94 & 4.50 & 4.73 \\
Total & 8.36 & 8.38 & 8.78 \\
\hline
\end{tabular}
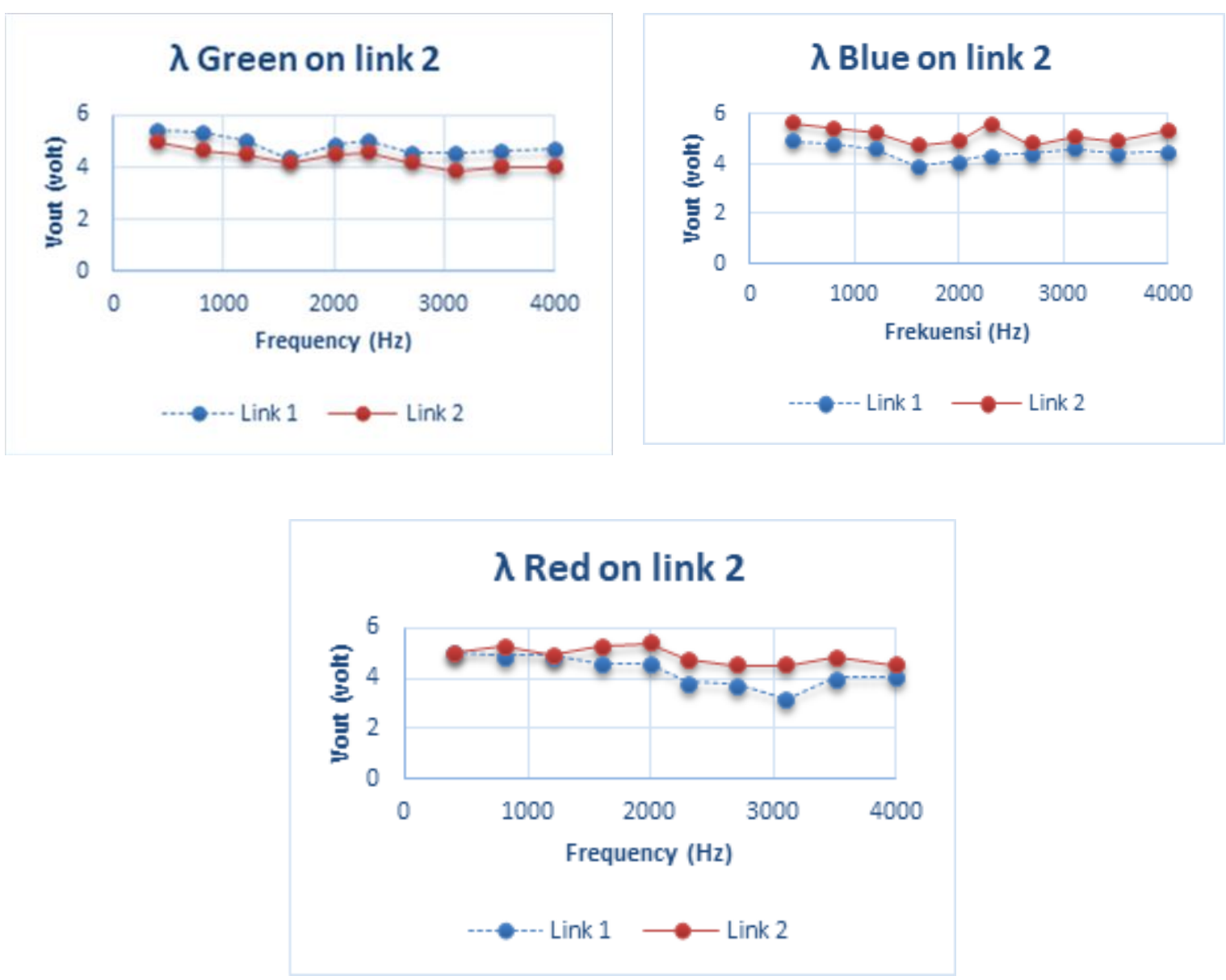

Figure 13. Measurement result where $\lambda$ green on link 


\subsection{Crosstalk Measurement}

To know the value of interference between the links, then the measurement of crosstalk by involving two links simultaneously but in the state of one of the links are not given signal information. In the measurement process, the information sent from link 1 has a distance of $50 \mathrm{~cm}$, and the value of crosstalk obtained from the output link two connected to the oscilloscope. Figure 14 is a block diagram of crosstalk measurement.

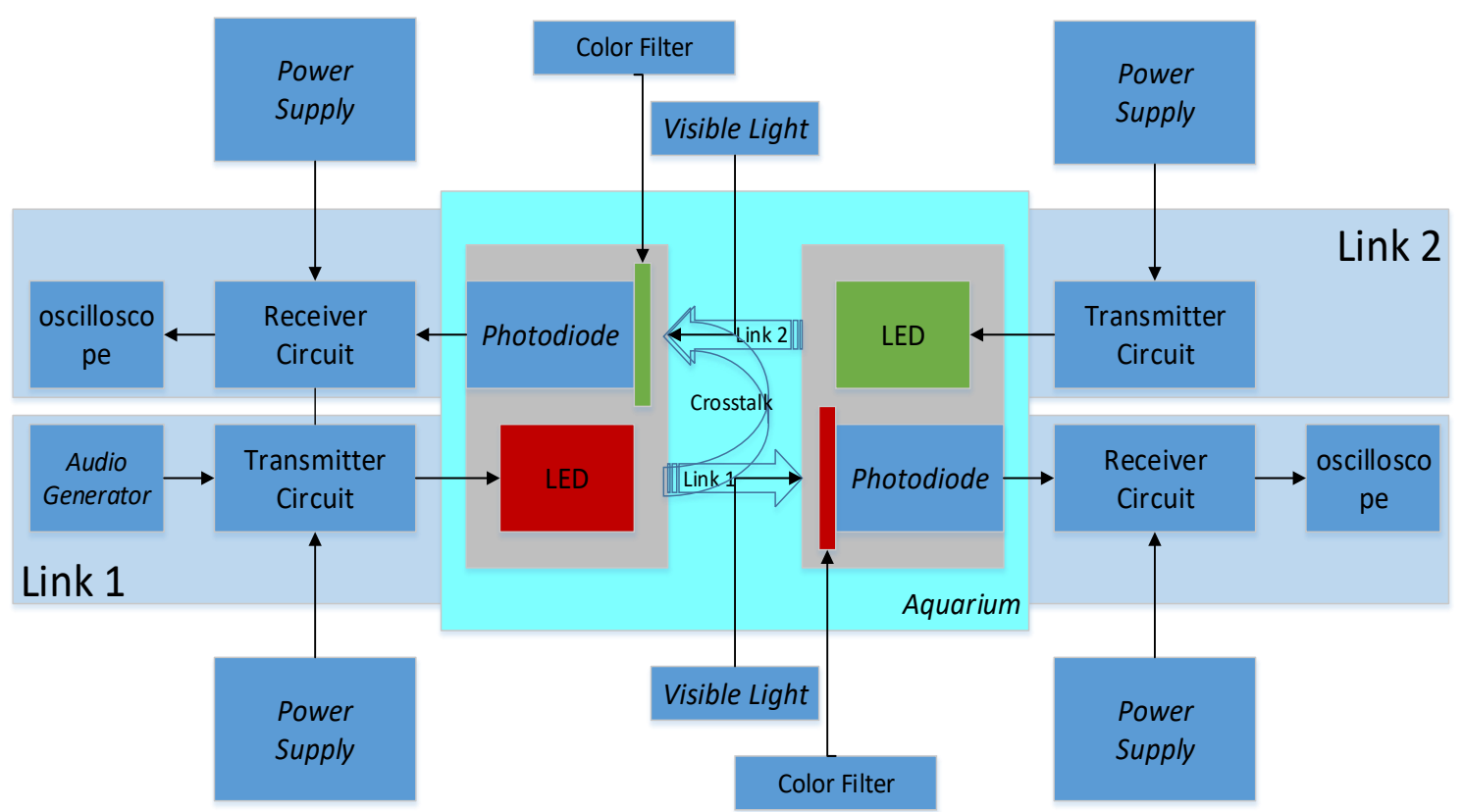

Figure 14. Crosstalk measurement diagram block using RGB LEDs

Figure 14 is diagram block of the previously mentioned conditions, subsequently for data retrieval, the transmitted frequency value of $1 \mathrm{~Hz}$ with the $5 \mathrm{Vp}$-p signal amplitude generated by the audio generator and for each link spacing of $50 \mathrm{~cm}$. In this crosstalk measurement, the color used is similar to the previous test, red $(\sim 675 \mathrm{~nm})$, blue $(\sim 470 \mathrm{~nm})$, and green $(\sim 550 \mathrm{~nm})$. Table 4 are the results of crosstalk measurements.

Table 4. Crosstalk Measurement Using RGB LEDs

\begin{tabular}{cccccc}
\hline Link 1 & Vout (Volt) & Freq $(\mathrm{Hz})$ & Link 2 & Vout (Volt) & Freq (Hz) \\
\hline \multirow{4}{*}{ Red } & 4.55 & 1029 & Red & 3.68 & 1093 \\
& 4.88 & 1006 & Blue & Unmeasured & Unmeasured \\
& 4.8 & 1009 & Green & Unmeasured & Unmeasured \\
\multirow{4}{*}{ Blue } & 4.88 & 1065 & Red & Unmeasured & Unmeasured \\
& 4.96 & 1067 & Blue & Unmeasured & Unmeasured \\
& 4.55 & 1007 & Green & Unmeasured & Unmeasured \\
\multirow{4}{*}{ Green } & 4.48 & 1028 & Red & Unmeasured & Unmeasured \\
& 4.48 & 1046 & Blue & Unmeasured & Unmeasured \\
& 4.71 & 1088 & Green & Unmeasured & Unmeasured \\
\hline
\end{tabular}

From the results obtained that the use of color filters is perfect regarding separation between links, it is shown from the discovery of information from link one on link 2. In the method of color LEDs precisely on the red one link and red link 2, there is crosstalk of $2.66 \mathrm{~dB}$. That value shows that bidirectional communication with a similar color causes leakage of information on link two that will cause a collision of the received information signal.

From all the experiments performed, the system can work bidirectional using color LEDs as well as wavelength separation that does work well, because there is no interference between links on the second wavelength condition of the different links. Conversely, if using a similar wavelength on each link, then the interference will occur. 


\section{CONCLUSION}

From the results of research Bidirectional Underwater Visible Light Communication System can be concluded, among others, as follows:

a. On the measurement of the system with two positions, the system with a direct position can work well and this is evidenced from the system can receive information signal with the average of the highest voltage value of 3.46 volts on the links 1 and 4.2 volts on link 2 .

b. On bidirectional system measurements using RGB LEDs instead of filters mounted on the LED front, a value of 8.90 volts is obtained and consists of a blue combination of link 1 and green on link 2 .

c. In crosstalk measurements with $1 \mathrm{kHz}$ frequency, the use of similar color LEDs can cause crosstalk, as in red - red, there is a crosstalk value of $2.66 \mathrm{~dB}$.

\section{ACKNOWLEDGEMENTS}

This research was supported by Hibah Penelitian Terapan Unggulan Perguruan Tinggi (PTUPT) 2018 funded by the Kementerian Riset, Teknologi, dan Pendidikan Tinggi Republik Indonesia.

\section{REFERENCES}

[1] "Underwater Robotics Group." [Online]. Available: http://www.sut.org/specialist-interest-group/underwaterrobotics-group.\%0AJanuary 10, 2018.

[2] G. Kaushal, Hemani \& Kaddoum, "Underwater optical wireless communication," IEEE access, vol. 4, no. 1, pp. 1518-1547, 2016.

[3] N. Shi, J., Huang, X., Wang, Y., \& Chi, "Real-time bidirectional visible light communication system utilizing a phosphor-based LED and RGB LED," in Sixth International Conference of Wireless Communications and Signal Processing (WCSP)., 2014.

[4] J.-H. C. Lanbo Lu, Shengli Zhou, "Prospects and problems of wireless communication for underwater sensor networks," Wirel. Commun. Mob. Comput., vol. 8, pp. 977-994, 2008.

[5] M. Doniec, C. Detweiler, I. Vasilescu, and D. Rus, "Using optical communication for remote underwater robot operation," IEEE/RSJ 2010 Int. Conf. Intell. Robot. Syst. IROS 2010 - Conf. Proc., pp. 4017-4022, 2010.

[6] R. M. Hagem, S. G. O'Keefe, T. Fickenscher, and D. V. Thiel, "Self contained adaptable optical wireless communications system for stroke rate during swimming," IEEE Sens. J., vol. 13, no. 8, pp. 3144-3151, 2013.

[7] A. R. Darlis, W. A. Cahyadi, and Y.-H. Chung, "Shore-to-Undersea Visible Light Communication," Wirel. Pers. Commun.,vol 99, no. 2, pp 681- 694, 2018. https://doi.org/10.1007/s11277-017-5136-9

[8] M. S. Rahman and K. Kim, "Indoor Positioning by LED Visible Light Communication and Image Sensors," Int. J. Electr. Comput. Eng., vol. 1, no. 2, pp. 161-170, 2011.

[9] C.Periasamy, K.Vimal, and D.Surender, "LED Lamp Based Visible Light Communication in Underwater Vehicles," Int. J. Eng. Trends Technol., vol. 13, no. 3, pp. 103-106, 2014.

[10] T. Fickenscher, J. Holborn, and D. V Thiel, "Underwater wireless optical communication for swimmer feedback using IrDA transceiver," Electron. Lett., vol. 47, no. 24, pp. 1335-1336, 2011.

[11] B. Tian, F. Zhang, and X. Tan, "Design and development of an LED-based optical communication system for autonomous underwater robots," 2013 IEEE/ASME Int. Conf. Adv. Intell. Mechatronics Mechatronics Hum. Wellbeing, AIM 2013, pp. 1558-1563, 2013.

[12] S. Fuada, A. P. Putra, Y. Aska and T. Adiono, "Noise Analysis of Trans-Impedance Amplifier (TIA) in Variety Op Amp for use in Visible Light Communication (VLC) System," International Journal of Electrical and Computer Engineering (IJECE), vol. 8, no. 1, pp. 159-171, 2018

[13] M. S. Rahman, M. M. Haque, and K. D. Kim, "Indoor Positioning by LED Visible Light Communication and Image Sensors," International Journal of Electrical and Computer Engineering (IJECE), vol. 1, no. 2, pp. 161170, 2011.

[14] A. Z. Suriza , S. Akter, and M. Shahnan, "Dimming Techniques for Visible Light Communication System," International Journal of Electrical Engineering and Computer Science (IJEECS), vol. 10, no. 1, pp. 258-265, 2018.

[15] S. R. Dominic C. O’Brien, Lubin Zeng, Hoa Le-Minh, Grahame Faulkner, Joachim W. Walewski, "Visible light communications: Challenges and possibilities," Personal, Indoor and Mobile Radio Communications, 2008. PIMRC 2008. IEEE 19th International Symposium on, 2008.

[16] B. Miguel and C. Silva, "Underwater Optical Communication an Approach Based on LED," pp. 4-5, 2015.

[17] C. Wang, H.-Y. Yu, and Y.-J. Zhu, "A Long Distance Underwater Visible Light Communication System With Single Photon Avalanche Diode," IEEE Photonics J., vol. 8, no. 5, pp. 1-11, 2016. 


\section{BIOGRAPHIES OF AUTHORS}

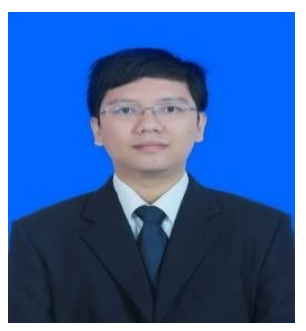

Arsyad Ramadhan Darlis received a B.Sc. on Electrical Engineering from Institut Teknologi Nasional Bandung, Indonesia in 2009 and an M.Sc. on Telecommunication Engineering from Institut Teknologi Bandung (ITB), Indonesia, in 2011, respectively. His research interests are underwater visible light communications, digital signal processing, and Internet-of-Things. He is currently a lecturer in Institut Teknologi Nasional Bandung.

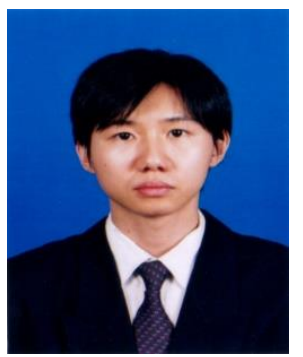

Andre Widura received a B.Sc. on Electrical Engineering from Maranata University, Indonesia in 2003 and an M.Sc. on Biomedical Engineering from Institut Teknologi Bandung (ITB), Indonesia, in 2010, respectively. His research interests are Internet-of-Things, networking, and instrumentation. He is currently a lecturer in Institut Teknologi Nasional Bandung.

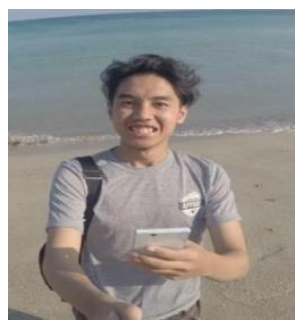

Muhamad Rifan Andrian received a B.Sc. on Electrical Engineering from Institut Teknologi Nasional Bandung, Indonesia in 2018. His research interests are visible light communication. 